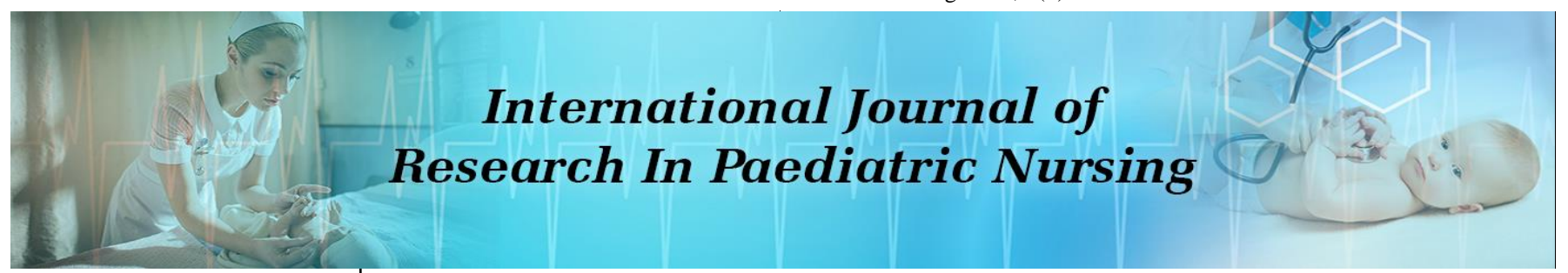

E-ISSN: 2664-1305 P-ISSN: 2664-1291 IJRPN 2020; 2(2): 81-89 http://www.paediatricnursing.net Received: 07-05-2020 Accepted: 10-06-2020

Hanaa Diab Khalafallha Cairo University, Faculty of Nursing, Ph.D. in Pediatric Nursing, Egypt

Nesren Sayed Mohamed Bahnsawy

(1). Cairo University, Faculty of Nursing, Ph.D. in Pediatric Nursing, Egypt

(2) King Saud Bin Abdulaziz University for Health Sciences, KSA, King Abdullah International Medical Research Center, Ministry of the National Guard, Health Affairs, College of Nursing, Pediatric Nursing, Riyadh, Saudi Arabia
Corresponding Author: Hanaa Diab Khalafallha Cairo University, Faculty of Nursing, Ph.D. in Pediatric Nursing, Egypt

\section{Effect of nursing instructions for mothers on selected cast outcomes among their infants with congenital clubfoot}

\author{
Hanaa Diab Khalafallha and Nesren Sayed Mohamed Bahnsawy
}

DOI: https://doi.org/10.33545/26641291.2020.v2.i2b.41

\begin{abstract}
Congenital clubfoot is a complex deformity that is readily apparent at birth and affects the muscles, ligaments, bones and joints of the developing foot and ankle. Aim of the current study was to evaluate the effect of nursing instructions for mothers on selected cast outcomes among their infants having congenital clubfoot. In order to represent the current research, the design of quasi-experimental was implemented. The study was conducted in the orthopedic out-patient clinic in the Cairo University Specialized Pediatric Hospital (CUSPH). Purposive sample of 60 mothers of infants with clubfoot was participated in the current study; mothers and their children were split into two equal groups: 30 as a control group and 30 as a study group. The data was collected using the following tools: structured interview questionnaire, mother's knowledge and practices assessment questionnaire (pre/posttest), recording cast complications sheet and selected cast outcomes assessment sheet. The results revealed that, there were statistically significant differences between total mean score of mother's knowledge and practices in the study group after receiving the nursing instructions than mothers in the control group. Infants in the study group exposed to less cast complications and better outcomes than infants in the control group. The result concluded that, the mothers in the study group who received nursing instructions had a higher overall mean score of clubfoot knowledge and practices rather than a control group. As well as the infants of the mothers who received the nursing instructions there were fewer complications of casting and better outcomes.
\end{abstract}

Keywords: Congenital clubfoot, mothers, infants, nursing instructions, cast complications and outcomes

\section{Introduction}

Clubfoot is a common type of birth defect that affects muscles and bones in the feet. New born can be born with the defect in one or both feet. It is estimated that the prevalence of congenital clubfoot worldwide is 1 to 4.5 per 1,000 live births and a $2: 1$ ratio of male to female, with about 50 percent of cases being bilateral. Every year, there are about 200,000 children born with clubfoot globally, $80 \%$ of whom are in low- and middle-income countries [1].

The causes of clubfoot are still unknown but found factors that lead to clubfoot are environmental, genetic, abnormal position in the utero, and anatomical factors. This is twisting which causes the toes to point toward the opposite leg ${ }^{[2]}$. If it is left untreated clubfoot deformity causes pain, difficulty in walking and inability to wear normal shoes ${ }^{[3]}$. In infancy, the majority of club feet can be corrected in about six to eight weeks with proper gentle manipulations and casting ${ }^{[4]}$.

The most common complications of cast in paediatric group are skin breakdown, pressure sores, discomfort or pain in the cast site, skin inflammation, swelling and joint stiffness. Additionally, risks associated with casting include loss of range of motion (ROM), muscle wasting and impaired circulation. Casts placed to treatment and encourage the mothers to assess cast daily to detect complications early and provide care for their infants at home ${ }^{[5]}$. The treatment is based on the critical interpretation of the functional anatomy of the feet in order to correct the position of the legs and gradually change the position of it through the manipulation and casting [6]. The most methods for clubfoot treatment are the Ponseti approach, which has been described as highly suitable for use in resource-limited environments ${ }^{[7]}$. The casting and Ponseti method had the greatest impact on the treatment of clubfoot, markedly reducing the need for extensive surgery ${ }^{[8]}$. The nurse roles are very crucial and it includes health teaching for the mothers to keep the cast clean and dry. Provide sponge bath, change diapers often to keep the clean cast. If the cast gets dirty, wipe it with a damp cloth. Check the circulation in foot every hour for the first 6-8 hours after a new cast 
and then a few times each day and check toes should be warm and pink. Put small towel under the knee. Also go to the hospital when cast cracks, skin inflammation and toes appear cyanosis ${ }^{[9]}$.

Caregivers of children with clubfoot play a very broad and important role. They're looking for care for their infant. Caregivers should be advised by the Orthopedic nurse to monitor changes in the skin of infants such as colour, redness, swelling, warmth, pain or other signs of infection at least once a day at the stage of damaged tissue ${ }^{[10]}$.

\subsection{Significance of the study}

The incidence rate of clubfoot in low-and middle-income countries affects about 174,000 babies each year, with $91 \%$ born ${ }^{[11]}$. Recent based on medical records and statistical affairs department in CUSPH, the overall number of infants admitted "from 2018 to 2019 " to the orthopedic pediatric surgery department was 1200 and 14.2 percent (170) of those infants had clubfoot. Via empiric experience in the CUSPH surgical unit, the researchers found that clubfoot children undergoing orthopedic correction increased significantly and considered that there was a high risk of casting complications that occurred over a long period of time. These problems have arisen as a result of a lack of nursing instructions about casting care for these infant and their families.

The retrospective study review of medical charts and records between 2000 and 2012 at Siriraj Hospital in Thailand by ${ }^{[5]}$ they studies complications associated with ponseti serial casting and surgical correction via soft tissue release in congenital idiopathic clubfoot was conducted that the goals of treatment are maintenance of flexible and avoid pain to the greatest achievable extent. Hence, cast complications and improper application of casts have contributed a burden for infant and their mothers and should be performer assessment for infant in follow up clinic to avoid several problems relative to their cast and found that approximately $29 \%$ of the visits were because of a wet cast, $10 \%$ of infants were secondary to a damaged cast, $23 \%$ complain of tight cast, $13 \%$ of them a loose cast and $10 \%$ suffer from pain.

Scares research studies were conducted nationally to help mothers caring for their infants with congenital clubfoot. Hence, the current study is undertaken to evaluate the effect of nursing instructions for mothers on selected cast outcomes among their infants having congenital clubfoot. Eventually, the results of the current study might generate an attention and motivation for further researches in the field of pediaric-orthopedic As well as providing guidance and recommendations that should be reflected in pediatric nursing education, practice and research.

\subsection{Operational definition \\ Selected cast outcomes}

For the purpose of the current study, the selected cast outcomes include early cast complications as (toes cyanosis, foot stiffens, pain and fever, foot swelling, skin breakdown, and skin inflammation it can be judged by measurement time of capillary refill, range of motion, pain scale, body temperature, assess foot swelling, assess skin condition and selected cast outcomes as (appearance of foot, straight of foot, gross motor mobility, range of motion and play activity).

\subsection{Aim of the study}

The aim of the current study was to evaluate the effect of nursing instructions for mothers on selected cast outcomes among their infants with congenital clubfoot.

\subsection{Research hypotheses}

H1: Mothers who receive the nursing instructions will have higher mean score of knowledge and practices regarding cast care those mothers in the control group.

$\mathrm{H} 2$ : Infant of mothers who receive the nursing instructions will have less cast complications than infant of mothers in the control group.

H3: Infant of the mothers who receive the nursing instructions will have better outcomes than infant of mothers in the control group.

\section{Methods and Subjects}

\subsection{Research design}

A pre-posttest quasi-experimental research design was used to achieve the aim of the current study. A quasi experimental design is one type of experimental design that is very similar to the true experimental design except there is lose one criteria as randomization ${ }^{[12]}$.

\subsection{Setting}

The study was conducted in the orthopedic out-patient clinic in the Cairo University Specialized Pediatric Hospital (CUSPH). Orthopedic clinic located at the second floor and received infant and children with orthopedic problem and postoperative follow up.

\subsection{Subjects}

Purposive sample of 60 mothers' of infants with clubfoot was participated in the study. The first 30 mothers and their infant were considered as a control group and received routine care in orthopedic clinic. The second 30 mothers and their infant were considered as a study group was subjected to the nursing instructions about cast care ${ }^{[13]}$.

\subsubsection{Inclusion criteria}

Infants up to one year.

- Infants diagnosed with unilateral or bilateral clubfoot.

- The mother is commitment with clinic's follow up schedule.

\subsubsection{Exclusion criteria}

Infants have other congenital anomalies such as (hydrocephalus, spina bifida and developmental dysplasia of the hip).

\subsection{Data collection tools}

The required tools developed and collected by researchers after reviewing the related literature through the following tools:

\subsubsection{Structured interview questionnaire}

It included personal data for the mother and infant: it involved nine (9) questions. Four (4) questions about mothers as: age, level of education, occupation, consanguinity. Also includes five (5) questions about characteristics of infant such as age, gender, residence, affected foot and affected gross motor.

\subsubsection{Mother's knowledge and practices assessment questionnaire (pre/posttest)}

It included the following two parts to assess mother's knowledge and practice which involved fifty questions. Part I: fifteen questions about knowledge as: clubfoot itself eight questions, feeding pattern five questions and two question for follow up. Part II: thirty-five questions about practice as: twenty-one questions of cast care, nine questions for 
hygienic care, five questions for range of motion, and play activity.

\subsubsection{Recording cast complications sheet}

It includes seven elements to assess cast complications as: toes cyanosis, foot stiffens, foot swelling, skin breakdown, skin inflammation, pain and fever.

\subsubsection{FLACC pain scale}

The researchers selected the valid and reliable FLACC pain Scale, the scale for pain evaluation was designed to provide such a standardized method for analyzing pain behaviors among infants who unable to verbalize the presence or severity of pain. Five fields are included in the scale: facial expression; leg movement; activity; cry; and consolation, each with 0 to 2 points.

\subsubsection{Selected cast outcomes assessment sheet}

It would include five elements to assess foot correction as appearance of foot, straight of foot, gross motor mobility, range of motion, and play activity.

\subsection{Scoring system}

For mothers' knowledge and practices; each complete response took " 2 " scores, the incomplete response took one " 1 " score and the wrong response or the don't known took "zero" score. The total score was 100 for fifty (50) questions and score was converted to $100 \%$, and then categorized as following: the total score less than $50 \%$ (less than 50 score) was considered as unsatisfactory while score of $50 \%$ and more (50 score and more) was considered as satisfactory level. The FLACC pain Scale ratings vary between 0 and 10 and are interpreted as follows: 0: no pain and relaxed; 1-3: mild pain; 4-6: Moderate and 7-10: Severe pain/discomfort.

\subsection{Validity and reliability}

The content validity of the tools assessed by 5 pediatric nursing and pediatric orthopedic experts. Cronbach's alpha for internal consistency reliability testing was carried out and the result was 0.82 and for the FLACC scale was 0.882

\subsection{Pilot study}

Pilot study was conducted on 6 mothers and their infants with clubfoot to ensure the clarity of content of tools and to assess the time needed to fill the tools. Minor modifications were done such as restate some wards. Based on the results of the pilot study, mothers of infants who participated in the pilot study were excluded in the total study sample.

\subsection{Procedure}

Official permissions were obtained from the directors of the Specialized Pediatric Hospital of Cairo University (CUSPH). Permission was also obtained from the head of the outpatient orthopedic clinic. Mothers and their infants who meet the inclusion criteria were asked to participate in the study. The purpose and essence of the research are individually explained to each mother. An individual interview with each mother for the purpose of gathering personal data for her as well as her child, and a pre-test collected by researchers from both study and control groups to evaluate the mother's knowledge in the waiting room before offering nursing instructions took 15 minutes to complete. The researchers then offered nursing instructions for mothers in the study group on an individual basis for three sessions (each one 45 minutes) and often for a group of mothers ranging from 3 to 5 mothers. The first session posted information on congenital anomalies such as clubfoot, including: description, forms, and symptoms, course of treatment, complications, and follow-up. The second and third session had nursing guidelines for the practice of cast care for clubfoot infants, covering cast care in the second session such as (position, handling, skin care and circulation assessment) and the third session covering hygiene care (bathing and diaper care), range of movement and play activity. To promote the comprehension of mothers, researchers had prepared and distributed to each mother an instructional illustrated Arabic booklet with an attractive image of acceptable cast care. Demonstration and re-demonstration of researchers' practices on a doll. After two weeks for both study and control group; the researchers filled posttest for study group to assess mothers' knowledge and practice after receiving nursing instructions. Regarding to control group the researchers filled posttest after received routine care from nurses in orthopedic clinic. The researchers assessed each infant in both the study and control group three times immediate cast, after three weeks and six weeks of cast, using a recording cast complications sheet to determine cast complications, and the session took 30 minutes to evaluate each child. The researchers observed and reported improvement of infant outcomes at the last time during the evaluation of the cast complication at six weeks by using selected cast outcomes assessment sheet and reported for each child in both study and control group and it took 30 minutes to evaluate each infant. Data collection was carried out over a fourteen-month period from January 2019 to February 2020.

\subsection{Ethical considerations}

Written consent obtained from the mothers of infants after complete description of the purpose and the nature of the study. Mothers and their infants were informed that participation in the study is voluntary. The researchers informed the mothers about their rights to withdraw from the study at any time without giving any reason and without any effect on the care of their infants and confidentiality assured to each infant and their mothers. For research ethical consideration and based on the basic ethical principles of beneficence, data will be collected firstly from the mothers and their infant in the control group. Upon the completion of data collection, Arabic instructions and booklets will be provided to the mothers of the control group regarding the care of their infants with cast

\subsection{Statistical analysis}

Using a compatible personal computer (PC), the data storage and analysis was carried out. The Social Studies Statistical Package (SPSS), Version 20, was chosen. Tabulating the data collected and summarizing it. Using suitable descriptive and inferential statistical tests, knowledge was computerized and analyzed. The frequency and percentage were expressed as qualitative information. The researchers used the parametric Chi square test to compare between qualitative variables. For the comparison of means the paired-sample t-test was selected. Using the Pearson correlation coefficient, correlation was achieved between variables. The significance level at $p<0.05$ was used as the value point for statistical. 


\section{Result}

Table 1: Percentage distribution of mother's characteristics in the study and control group

\begin{tabular}{|c|c|c|c|c|c|c|}
\hline \multirow[t]{2}{*}{ Items } & \multicolumn{2}{|c|}{$\begin{array}{c}\text { Study group } \\
(\mathbf{n}=\mathbf{3 0})\end{array}$} & \multicolumn{2}{|c|}{$\begin{array}{c}\text { Control group } \\
(\mathbf{n}=\mathbf{3 0})\end{array}$} & \multirow[t]{2}{*}{$\mathbf{X}^{2}$} & \multirow[t]{2}{*}{$\mathbf{P}$} \\
\hline & $\mathbf{N}$ & $\%$ & $\mathbf{N}$ & $\%$ & & \\
\hline \multicolumn{7}{|c|}{ Mother's age/years } \\
\hline$>20$ & 3 & 10 & 3 & 10 & \multirow{3}{*}{6.52} & \multirow{3}{*}{.367} \\
\hline $20:>30$ & 17 & 56.7 & 16 & 53.3 & & \\
\hline $30:>40$ & 10 & 33.3 & 11 & 36.7 & & \\
\hline Mean \pm SD & \multicolumn{2}{|c|}{$29.10 \pm 6.81$} & \multicolumn{2}{|c|}{$27.63 \pm 6.09$} & & \\
\hline \multicolumn{7}{|c|}{ Level of education } \\
\hline Didn't read or write & 3 & 10 & 4 & 13.3 & & \\
\hline Primary school education & 9 & 30 & 11 & 36.7 & 6.12 & .728 \\
\hline Diploma & 18 & 60 & 15 & 50 & & \\
\hline \multicolumn{7}{|c|}{ Mother's job } \\
\hline Housewife & 21 & 70 & 26 & 86.7 & 870 & 325 \\
\hline Working mother & 9 & 30 & 4 & 13.3 & 8.19 & (34) \\
\hline \multicolumn{7}{|c|}{ Consanguinity } \\
\hline Yes & 15 & 50 & 17 & 56.7 & \multirow{2}{*}{3.39} & \multirow{2}{*}{$0.05 *$} \\
\hline No & 15 & 50 & 13 & 43.3 & & \\
\hline
\end{tabular}

Table (1) clarified that more than half of mothers in both the study and control groups their age ranged from 20 to less than 30 years. The mean age was $29.10 \pm 6.81$ years for mothers in the study group and $27.63 \pm 6.09$ of them in the control group. Regarding mothers' level of education, it was found that (60\% \& 50\% respectively) in the both study and control group had diploma education. In relation to their occupation, it was found that $(70 \% \& 86.7 \%$, respectively) of mothers in both groups were housewives and $(50 \%$ \& $56.7 \%$, respectively) had consanguineous marriages in both groups, as stated by mothers. The same table indicated that there was a statistically significant difference in consanguinity between infants in both the study and control groups $(\mathrm{X} 2=3.39, \mathrm{p}=0.05)$.

Table 2: Percentage distribution of personal characteristics of infants with clubfoot in the study and control group

\begin{tabular}{|c|c|c|c|c|c|c|}
\hline \multirow[t]{2}{*}{ Items } & \multicolumn{2}{|c|}{$\begin{array}{l}\text { Study group } \\
\quad(\mathbf{n}=\mathbf{3 0})\end{array}$} & \multicolumn{2}{|c|}{$\begin{array}{l}\text { Control group } \\
\quad(\mathbf{n}=\mathbf{3 0})\end{array}$} & \multirow[t]{2}{*}{$\mathbf{X}^{2}$} & \multirow[t]{2}{*}{$\mathbf{P}$} \\
\hline & $\mathbf{N}$ & $\%$ & $\mathbf{N}$ & $\%$ & & \\
\hline \multicolumn{7}{|c|}{ Infants age } \\
\hline$<6$ months & 18 & 60 & 16 & 53.3 & & \\
\hline 6 months to 1 year & 12 & 40 & 14 & 46.7 & 3.15 & .533 \\
\hline Mean +SD & \multicolumn{2}{|c|}{$5.43+3.46$} & \multicolumn{2}{|c|}{$4.90+3.41$} & & \\
\hline \multicolumn{7}{|c|}{ Gender } \\
\hline Male & 18 & 60 & 24 & 80 & & \\
\hline Female & 12 & 20 & 6 & 20 & .139 & .545 \\
\hline \multicolumn{7}{|c|}{ Place of residence } \\
\hline Urban & 7 & 23.3 & 16 & 53.3 & & \\
\hline Rural & 23 & 76.7 & 14 & 46.7 & 2.24 & $.043^{*}$ \\
\hline \multicolumn{7}{|c|}{ Affected gross motor } \\
\hline Setting & 9 & 30 & 13 & 43.3 & & \\
\hline Creeping & 15 & 50 & 14 & 46.7 & 4.40 & $.054 *$ \\
\hline Standing & 6 & 20 & 3 & 10 & & \\
\hline \multicolumn{7}{|c|}{ Affected foot } \\
\hline Bilateral & 22 & 73.3 & 17 & 56.7 & & \\
\hline Unilateral & 8 & 26.7 & 13 & 43.3 & 1.97 & .485 \\
\hline
\end{tabular}

Table (2) revealed that less than two thirds $(60 \%)$ of infants in the study group having clubfoot and $53.3 \%$ of infants in the control group their age were less than 6 months. Their mean age was $5.43 \pm 3.46$ months in the study group and $4.90 \pm 3.41$ of them in the control group. Less than two thirds $(60 \%)$ of the studied infants and the majority $(80 \%)$ of the control group were males. It was found that, $76.7 \%$ of infants in the study live in rural areas. While, $53.3 \%$ of them in the control groups live in urban areas. Regarding to gross motor defect, $(50 \%, 46.7 \%$ respectively) of infants in the both groups was unable to creeping and (30\%, $43.3 \%$ respectively) in both groups unable to setting. Although, it was found that $(73.3 \%, 56.7 \%$, respectively) both the study and control group had bilateral clubfoot. The same table indicated that there was a statistically significant difference between infants in both study and control groups regarding to place of residence and affected gross $\left(X^{2}=2.24, p=.043\right.$, $\mathrm{X}^{2}=4.40, \mathrm{p}=.054$, respectively). 
Table 3: Comparison of between total mean score of mothers' knowledge pre and posttest nursing instructions

\begin{tabular}{|c|c|c|c|c|c|c|c|c|}
\hline \multirow{3}{*}{ Items } & \multicolumn{2}{|c|}{ Study group $(n=30)$} & \multirow{3}{*}{$\mathbf{T}$} & \multirow{3}{*}{$\mathbf{P}$} & \multicolumn{2}{|c|}{ Control group $(n=30)$} & \multirow{3}{*}{$\mathbf{T}$} & \multirow{3}{*}{$\mathbf{P}$} \\
\hline & Pre-test & Post-test & & & Pre-test & Post-test & & \\
\hline & Mean \pm SD & Mean \pm SD & & & Mean \pm SD & Mean \pm SD & & \\
\hline Club foot (16 marks) & $4.70 \pm 1.87$ & $12.26 \pm 2.66$ & -13.07 & .000 & $5.73 \pm 2.63$ & $5.83 \pm 1.36$ & -.223 & .825 \\
\hline Feeding (10 marks) & $3.40 \pm 1.22$ & $8.03 \pm 1.56$ & -12.85 & .000 & $3.46 \pm 1.16$ & $3.26 \pm 1.20$ & .711 & .483 \\
\hline Follow up (4 marks) & $1.83 \pm .592$ & $3.46 \pm .730$ & -11.06 & .000 & $2.56 \pm .858$ & $2.10 \pm .844$ & 3.29 & .003 \\
\hline
\end{tabular}

Table (3) highlighted that, the total mean scores of mothers' knowledge in study group before receiving the nursing instructions were $4.70 \pm 1.87,3.40 \pm 1.22$ and $1.83 \pm .592$ respectively. While, total mean scores of mothers' knowledge increased after receiving the nursing instructions to $12.26 \pm 2.66,8.03 \pm 1.56$ and $3.46 \pm .730$ respectively. Although, there were statistically significant differences were detected between total mean score of mother's knowledge in the study group before and after receiving the nursing instructions at $(p<0.01)$. On the other hand, the total mean scores of mother's knowledge in the control group before and after receiving routine of care were nearly scored to each other. No statistically significant differences were detected between the total mean score of mothers' knowledge in the control group.

Table 4: Comparison of between total mean score of mothers' practices pre and posttest nursing instructions

\begin{tabular}{|c|c|c|c|c|c|c|c|c|}
\hline \multirow{3}{*}{ Mothers practices } & \multicolumn{2}{|c|}{ Study group $(n=30)$} & \multirow{3}{*}{$\mathbf{T}$} & \multirow{3}{*}{$\mathbf{P}$} & \multicolumn{2}{|c|}{ Control group $(n=30)$} & \multirow{3}{*}{$\mathbf{t}$} & \multirow{3}{*}{$\mathbf{P}$} \\
\hline & Pre-test & Post-test & & & Pre-test & Post-test & & \\
\hline & Mean \pm SD & Mean \pm SD & & & Mean \pm SD & Mean \pm SD & & \\
\hline Care of cast (42 marks) & $16.83 \pm 4.39$ & $33.76 \pm 4.06$ & -15.29 & .000 & $15.03 \pm 3.29$ & $15.96 \pm 2.63$ & -2.19 & .037 \\
\hline hygienic care (18 marks) & $8.50 \pm 2.84$ & $15.20 \pm 1.56$ & -12.44 & .000 & $8.73 \pm 1.72$ & $9.13 \pm 1.54$ & -1.02 & .315 \\
\hline Range of motion \& Play activity (10 marks) & $2.93 \pm .944$ & $7.73 \pm 1.74$ & -13.83 & .000 & $3.13 \pm 1.16$ & $2.83 \pm 1.11$ & 1.10 & .279 \\
\hline
\end{tabular}

Table (4) indicted that, the total mean scores of mothers' practices in study group before receiving the nursing instructions were $16.83 \pm 4.39,8.50 \pm 2.84$ and $2.93 \pm .944$ respectively. While, total mean scores of mothers' practices increased after receiving the nursing instructions to, $33.76 \pm$ $4.06,15.20 \pm 1.56$ and $7.73 \pm 1.74$ respectively. Although, there were statistically significant differences were detected between total mean score of mother's practices in the study group before and after receiving the nursing instructions at $(p<0.01)$. On the other hand, the total mean scores of mother's practices in the control group before and after receiving routine of care were nearly scored to each other. No statistically significant differences were detected between the total mean score of mothers' practices in the control group.

Table 5: Comparison between mother's level of knowledge and practices pre and posttest nursing instructions

\begin{tabular}{|c|c|c|c|c|c|c|c|c|c|c|c|c|}
\hline \multirow{3}{*}{ Level of knowledge } & \multicolumn{4}{|c|}{ Study group $(\mathrm{n}=\mathbf{3 0})$} & \multirow{3}{*}{$\mathbf{X}^{2}$} & \multirow{3}{*}{$\mathbf{P}$} & \multicolumn{4}{|c|}{ Control group $(\mathbf{n}=\mathbf{3 0})$} & \multirow{3}{*}{$\mathbf{X}^{2}$} & \multirow{3}{*}{$\mathbf{P}$} \\
\hline & \multicolumn{2}{|c|}{ Pretest } & \multicolumn{2}{|c|}{ Posttest } & & & & & & est & & \\
\hline & No & $\%$ & No & $\%$ & & & No & $\%$ & No & $\%$ & & \\
\hline Satisfactory & 9 & 30 & 24 & 80 & \multirow{2}{*}{19.20} & \multirow{2}{*}{$.000 *$} & 6 & 20 & 7 & 23.3 & \multirow{2}{*}{8.53} & \multirow{2}{*}{3.23} \\
\hline Unsatisfactory & 21 & 70 & 6 & 20 & & & 24 & 80 & 23 & 76.7 & & \\
\hline
\end{tabular}

Table (5) indicated that, 70\%of mothers had an unsatisfactory level of knowledge and practices in the study group before receiving the nursing instructions compared to majority of mothers had a satisfactory level of knowledge and practices after receiving the nursing instructions. On the same line, $(80 \%, 76.7$ respectively) of mothers had an unsatisfactory level of knowledge and practices in the control group before and after receiving routine of care. Statistically significant differences were detected in the study group between mothers' level of information and their practices before and after receiving nursing instructions at $(p<0.01)$.

Table 6: Comparison of overall mean score for mothers' knowledge and practices in the study and control groups after nursing instructions

\begin{tabular}{|c|c|c|c|c|}
\hline Item & Study group $(\mathbf{n}=\mathbf{3 0})$ & Control group $(\mathbf{n}=\mathbf{3 0})$ & T & P \\
\hline Mean \pm SD & $80.26 \pm 16.49$ & \pm 5.6146 .76 & -10.88 & .000 \\
\hline
\end{tabular}

Table (6) Illustrated that there was a statistically significant difference between the overall mean knowledge and practice score for mothers in the study and control group after receiving nursing instructions at $(\mathrm{t}=-10.88, \mathrm{p}=<0.01)$ and the mean of the study group was $80.26 \pm 16.49$ and the mean in the control group was $4676 . \pm 5.61$. 
Table 7: Comparison of cast complications between infant with clubfoot in the study and control group

\begin{tabular}{|c|c|c|c|c|c|c|c|c|c|c|c|c|c|c|}
\hline \multirow{3}{*}{ Items } & \multicolumn{6}{|c|}{ Study group $(n=30)$} & \multicolumn{6}{|c|}{ Control group $(\mathbf{n}=30)$} & \multirow{3}{*}{$\mathbf{X}^{2}$} & \multirow{3}{*}{$\mathbf{P}$} \\
\hline & \multicolumn{2}{|c|}{ Immediate } & \multicolumn{2}{|c|}{3 weeks } & \multicolumn{2}{|c|}{6 weeks } & \multicolumn{2}{|c|}{ Immediate } & \multicolumn{2}{|c|}{3 weeks } & \multicolumn{2}{|c|}{6 weeks } & & \\
\hline & $\mathbf{N}$ & $\%$ & $\mathbf{N}$ & $\%$ & $\mathbf{N}$ & $\%$ & $\mathbf{N}$ & $\%$ & $\mathbf{N}$ & $\%$ & $\mathbf{N}$ & $\%$ & & \\
\hline \multicolumn{15}{|c|}{ Toes cyanosis } \\
\hline $\mathrm{P}$ & 5 & 16.7 & 2 & 6.7 & 0 & 0 & 17 & 56.7 & 13 & 43.3 & 10 & 46.7 & 740 & (047* \\
\hline N.P & 25 & 83.3 & 28 & 93.3 & 30 & 100 & 13 & 43.3 & 17 & 56.7 & 20 & 53.3 & .149 & $.042^{*}$ \\
\hline \multicolumn{15}{|c|}{ Foot stiffens } \\
\hline$P$ & 4 & 13.3 & 3 & 10 & 1 & 3.3 & 12 & 40 & 10 & 33.3 & 10 & 33.3 & & \\
\hline N.P & 26 & 86.7 & 27 & 90 & 29 & 96.7 & 18 & 60 & 20 & 66.7 & 20 & 66.7 & .517 & $.015^{*}$ \\
\hline \multicolumn{15}{|c|}{ Foot Swelling } \\
\hline $\mathrm{P}$ & 0 & 0 & 7 & 23.3 & 2 & 6.7 & 0 & 0 & 19 & 63.3 & 26 & 86.7 & & \\
\hline N.P & 30 & 100 & 23 & 76.7 & 28 & 93.3 & 30 & 100 & 11 & 36.7 & 4 & 13.3 & 3.33 & $.046^{*}$ \\
\hline \multicolumn{15}{|c|}{ Skin breakdown } \\
\hline $\mathrm{P}$ & 0 & 0 & 4 & 13.3 & 3 & 10 & 0 & 0 & 13 & 43.3 & 23 & 76.7 & & \\
\hline N.P & 30 & 100 & 26 & 86.7 & 27 & 90 & 30 & 100 & 17 & 56.7 & 7 & 23.3 & 4.53 & $.054 *$ \\
\hline \multicolumn{15}{|c|}{ Skin inflammation } \\
\hline $\mathrm{P}$ & 0 & 0 & 8 & 26.7 & 4 & 13.3 & 0 & 0 & 14 & 46.7 & 27 & 90 & & \\
\hline N.P & 30 & 100 & 22 & 73.3 & 26 & 86.7 & 30 & 100 & 16 & 53.3 & 3 & 10 & 6.67 & $.013^{*}$ \\
\hline \multicolumn{15}{|c|}{ Fever } \\
\hline $\mathrm{P}$ & 18 & 60 & 4 & 13.3 & 2 & 6.7 & 22 & 73.3 & 15 & 50 & 12 & 40 & & \\
\hline N.P & 12 & 40 & 26 & 86.7 & 28 & 93.3 & 8 & 26.7 & 15 & 50 & 18 & 60 & 1.63 & .201 \\
\hline \multicolumn{15}{|c|}{ Pain intensity } \\
\hline Non & 10 & 33.3 & 12 & 40 & 22 & 73.3 & 9 & 30 & 8 & 26.7 & 9 & 30 & & \\
\hline Mild & 11 & 36.7 & 8 & 26.7 & 3 & 10 & 9 & 30 & 5 & 16.7 & 6 & 20 & & \\
\hline Moderate & 5 & 16.7 & 7 & 23.3 & 2 & 6.7 & 8 & 26.7 & 9 & 30 & 8 & 26.7 & 3.47 & $.032^{*}$ \\
\hline Sever & 4 & 13.3 & 3 & 10 & 3 & 10 & 4 & 13.3 & 8 & 26.7 & 7 & 23.3 & & \\
\hline
\end{tabular}

* Significant at $P<0.05(\mathrm{P}=$ Present, N.P = Not Present $)$

Table (7) documented that all (100) of infants in study group had no change of colour in the toes, compared to (46.7\%) of the control group. The Vast majority (96.7\%) of infants in study group had no foot stiffening, while onethird $(33.3 \%)$ of infants in the control group had no foot stiffening. It was evident from table that majority of infants in the study group were not suffered from foot swelling, skin break down and skin inflammation compared to $(86.7 \%, 76.7 \%, \& 90 \%$ respectively) in the control group had it. $40 \%, 86.7 \%$ and $93.3 \%$ respectively of infants in study group didn't have fever, neither immediately, after three weeks or after six weeks this percentage increase $(73.3 \%, 50 \%$, and $40 \%$, in order) in the control group. Regarding to pain intensity, it was found that only (33.3\%, $40 \%, 73.3 \%$ respectively) of infants in the study group had no pain compared to infants in the control group complain from moderate and sever pain $(26.7 \%, 23.3 \%$ respectively) at six weeks. The same table demonstrated that there was a statistically significant difference regarding to toes cyanosis, foot stiffens, foot swelling, skin breakdown, skin inflammation and pain at $P \leq 0.05$.

Table 8: Percentage distribution of infant outcomes in the study and control group

\begin{tabular}{|c|c|c|c|c|c|c|}
\hline \multirow[t]{2}{*}{ Outcomes } & \multicolumn{2}{|c|}{$\begin{array}{l}\text { Study group } \\
(\mathrm{n}=\mathbf{3 0})\end{array}$} & \multicolumn{2}{|c|}{$\begin{array}{c}\text { Control group } \\
(\mathbf{n}=\mathbf{3 0})\end{array}$} & \multirow[t]{2}{*}{$\mathbf{X}^{2}$} & \multirow[t]{2}{*}{$\mathbf{P}$} \\
\hline & $\mathbf{N}$ & $\%$ & $\mathbf{N}$ & $\%$ & & \\
\hline \multicolumn{7}{|c|}{ Appearance of foot } \\
\hline $\begin{array}{c}\text { Normal } \\
\text { Abnormal }\end{array}$ & $\begin{array}{c}22 \\
8\end{array}$ & $\begin{array}{l}73.3 \\
26.7\end{array}$ & $\begin{array}{l}13 \\
17\end{array}$ & $\begin{array}{l}43.3 \\
56.7\end{array}$ & 5.11 & $.031 *$ \\
\hline \multicolumn{7}{|c|}{ Straight of foot } \\
\hline $\begin{array}{l}\text { Not corrected } \\
\text { Mild correction } \\
\text { Corrected } \\
\end{array}$ & $\begin{array}{c}1 \\
12 \\
17 \\
\end{array}$ & $\begin{array}{c}3.3 \\
40 \\
56.7 \\
\end{array}$ & $\begin{array}{c}5 \\
18 \\
7 \\
\end{array}$ & $\begin{array}{c}16.7 \\
60 \\
23.3 \\
\end{array}$ & 2.75 & $.041 *$ \\
\hline \multicolumn{7}{|c|}{ Gross motor mobility } \\
\hline $\begin{array}{c}\text { Achieved } \\
\text { Not achieved }\end{array}$ & $\begin{array}{c}27 \\
3\end{array}$ & $\begin{array}{l}90 \\
10\end{array}$ & $\begin{array}{l}16 \\
14\end{array}$ & $\begin{array}{l}53.3 \\
46.7\end{array}$ & .563 & .448 \\
\hline \multicolumn{7}{|c|}{ Range of motion } \\
\hline $\begin{array}{l}\text { Passive } \\
\text { Active }\end{array}$ & $\begin{array}{c}9 \\
21\end{array}$ & $\begin{array}{l}30 \\
70\end{array}$ & $\begin{array}{c}26 \\
4\end{array}$ & $\begin{array}{l}86.7 \\
13.3\end{array}$ & 5.19 & $0.03 *$ \\
\hline \multicolumn{7}{|c|}{ Play activity } \\
\hline $\begin{array}{c}\text { Active } \\
\text { Limited }\end{array}$ & $\begin{array}{c}26 \\
4\end{array}$ & $\begin{array}{l}86.7 \\
13.3\end{array}$ & $\begin{array}{c}3 \\
27\end{array}$ & $\begin{array}{l}10 \\
90\end{array}$ & 9.23 & $.003 *$ \\
\hline
\end{tabular}

* Significant at $P<0.5$

It was clear from table (8) that more than two thirds of infant had normal appearance of foot. While, it was found among $43.3 \%$ of infant in the control group and $(56.7 \%$, $16.7 \%$ respectively) of infant in both groups had straight foot. Regarding to gross motor mobility $90 \%$ and $53.3 \%$ of infant in both groups achieved it. $70 \%$ of infants in the study group were active in the range of motion. Although, majority of infants in the control group had passive range of 
motion and majority of infants in study group had active play activity compared to $90 \%$ of infants in the control group had limited play activity. The same table showed statistically significant differences in appearance and straight of foot, range of motion, and play activity between infants in both study and control groups at $P \leq 0.05$.

Table 9: Correlation between selected mother's personal data and overall means score of knowledge and practice after nursing instructions in the study group

\begin{tabular}{|c|c|c|}
\hline \multirow{2}{*}{ Item } & \multicolumn{2}{|c|}{ Overall mean score } \\
\cline { 2 - 3 } & $\mathbf{r}$ & $\mathbf{P}$ \\
\hline Age & 25.00 & $.000^{* *}$ \\
\hline Level of education & 24.13 & $.000^{* *}$ \\
\hline Occupation & 3.00 & .083 \\
\hline Place of residence & 2.00 & .157 \\
\hline
\end{tabular}

** Significant at $P<0.01$

Table (9) revealed that there was a statistically significant positive correlation between the overall mean score of mothers' knowledge and practice and their mother's age and level of education. There were no statistically significant correlations between the overall mean score of mothers' knowledge and practice and their occupation and place of residence.

\section{Discussion}

The results of the current study revealed that less than twothirds of infants in the study group and more than half of infant in the control group their age were less than six months and the mean age in both groups was $(.586 \pm .589$, $507 \pm .591$ respectively). These results were supported by ${ }^{[3]}$ they studied the treatment of congenital clubfoot and found that $45 \%$ of infants their age were four months and the mean aged was $1.62 \pm 0.898$ months. As well as, ${ }^{[14]}$. They concluded that $64.86 \%$ of infants in six months and less than six months of follow-up to Ponseti's technique had excellent results.

Concerning infant gender and place of residence, less than two-thirds of the studied infants and majority of them in the control group were males and more than half of infants in the control groups live in urban areas. This result congruent with ${ }^{[15]}$ who found that clubfoot is more common in males than females with an approximate ratio 5:1. On the same line ${ }^{[3]}$ they reported that more than two- thirds were males and $60.3 \%$ of them live in urban area. From the researchers view the habit of nutrition for pregnant women in urban area during pregnant period and deficiency of folic acid lead to increased incidence of congenital anomalies.

As regards to infant immobility, the highest presence of infants in both study and control group were unable to creep. This result was confirmed by [16] they studied manipulation and brace fixing for the treatment 465 of congenital clubfoot in newborns and infants and found that untreated clubfoot will suffer in their daily life activities such as difficulties in gait patterns, mobility, daily living skills, and social activities and walking. It was evident from the results of the current study that the highest proportion of infants in both groups had bilateral clubfoot. These results were supported by ${ }^{[17]}$ the studies of congenital clubfoot and found that half of the cases were bilateral clubfoot and the right side was more commonly affected than the left.

In relation to mothers' age the results of the recent study show that more than half of mothers in both groups were between 20 and less than 30 years of age. This result contradicted [18] who studied the relationship between maternal age at the estimated date of delivery and the risk of birth defects based on these findings, in the United States, younger maternal age $>20$ years and $<40$ years had an incidence of birth defect.

Regarding mothers' level of education, it was found that two-thirds and half of mothers in both groups had diploma education. This result contradictory with ${ }^{[19]}$ they found that about $59.8 \%$ of mothers' educational status was up to the primary level and $21.6 \%$ of them were at the secondary level. From the researchers view the level of education had impact to improve quality of care for their infants and a key factor that influencing interactions during nursing instructions sessions.

As regards mothers' occupation, the study results proved that more than two thirds of mothers in study group and majority of them in control group were housewives. As well as [20] they indicated that the majority of mothers were housewives. From the researcher point of view, most of Egyptian mothers preferred to stay at home to provide care for their husbands and children specially, if they had a chronic ill member in the family. As regards mothers' consanguineous, the study results proved that the highest percentage in both study and control groups had a consanguineous marriage. According to ${ }^{[21]}$, they reported that mothers in their study had a higher prevalence of maternal risk factors related to consanguinity which lead to congenital anomalies in Beni-Suef city.

In relation to level of knowledge and practices before and after receiving nursing instructions, it was highlighted that majority of mothers of infants with clubfoot in both study and control groups had unsatisfactory level of mothers' knowledge and practices before implementation of nursing instructions. The finding went in the same line with ${ }^{[10]}$ explored that intrapersonal barriers experienced were a lack of income and additional responsibilities and reported that insufficient information about treatments and challenges following treatment included counselling sessions lead to more relapse infant again. On the same line, ${ }^{[18]}$ reported that $52.9 \%(\mathrm{n}=54)$ parents have lack of knowledge about how to use the brace and $9.8 \%(\mathrm{n}=10)$ didn't identify the follow up time.

The current study indicated that, the vast majority infant mothers with clubfoot in the study group had a satisfactory level of knowledge and practices after teaching instructions. The finding was in the same line with ${ }^{[22]}$ found that mothers in the treated group reported a protective role for social support. Moreover, they highlighted the importance of implementing protocols in the hospital unit directed to parents of babies with congenital anomalies. The results show only a trend towards a higher impact of health teaching during the casting phase.

It was evident in the results of the current study that, a statistically significant difference between the overall mean knowledge and practice score for mothers in the study and control group after receiving nursing instructions at $(\mathrm{t}=-$ $10.88, \mathrm{p}=<0.01$ ) and the mean \pm SD of study group was $80.26 \pm 16.49$ and the mean \pm SD in the control group was $46.76 \pm 5.61$. This could be related to that mothers in the control group had received the routine hospital care which unfortunately, had not been informed of the appropriate cast care needed for their infants. These results indicate the effectiveness of the nursing instruction on improving 
mothers' knowledge and practices in the study group. Furthermore, [23] they studied clubfoot treatment after manipulation and casting using the ponseti method and documented that with Ponseti manipulation and casting, the majority of infants with clubfoot can achieve a satisfactory outcome with an increase in parent education level and a mean management score of $3.80 \pm 1.15$ and $\mathrm{P}$ value < 0.0001 .

Clearly, the study's results indicated that the vast majority of infants in the study group did not complain of stiffening of their feet, while one-third were infants in the control group. Regarding to pain, less than one quarter of infants in the study group had pain but more than two thirds of infants in the control group had pain. The findings contradictory with [24] who concluded that serious complications are uncommon and depend on the type of surgery performed such as vascular necrosis, infection, pain, stiffness and relapse.

Explicitly, the study's results indicated that less than one quarter of infants in the study group had foot swelling and skin inflammation compared to majority of infants in the control group. This result supported with ${ }^{[25]}$ they indicated that treatment complications of the Ponseti method include ulcers, swellings, abrasions, bleeding and delayed healing after surgical correction.

In relation to skin breakdown, ten percent of infants in the study group had a skin breakdown compare to more than three quarters of infants in the control group. This was supported with ${ }^{[26]}$ they found the same phenomenon when they studied complications associated with ponseti serial casting and surgical correction via soft tissue release in congenital idiopathic clubfoot, the two most common complications of Ponseti serial casting were cast loosening and cast-associated skin irritation $(5.48 \%)$ and wound infection $(5.26 \%)$.

The current study's results illustrated that the vast majority of infants in study group did not have fever after six weeks of associated casting complications this percentage increase of fever occurrence in the control group to forty percent. This result agreement with ${ }^{[27]}$ who reported that infants commonly complained during casting had temporary edema of the foot and fever. As regards child's outcomes the study results showed that, more than two thirds of infants in the study group had a normal appearance of foot. This result congruent with ${ }^{[28]}$ they found that seventy-six percent of the infants treated according to the traditional method and Ponseti had normal motor abilities.

As regarding to range of motion, more than two thirds of infants in the study group had active range of motion and majority of infants in control group had passive range of motion. Similar to ${ }^{[23]}$ most children with the correct and secure casting obtain a good result and have an active range of motion with the method of manipulation and casting of Ponseti. On the same line, the majority of infants in study group were active participants in play activities. This result contrasts with ${ }^{[29]}$ they reported that, in Canada, a national study of cases reported to infant welfare services found that, among the substantiated cases of neglect, nineteen percent involved physical neglect, twelve percent abandonment, eleven percent educational neglect, and forty-eight percent physical harm resulting from a parent's failure to provide adequate supervision. From the researchers view these different types of parental neglect in their infants leading to a decrease in daily activity and a decrease curiosity between the environment and the infants. It was found that, there was a statistically significant positive correlation between the overall mean score of mothers' knowledge and practice and their age and level of education. This explanation was in the same line with ${ }^{[30]}$ they reported that the mothers' roles during the time of treatment for providing care and observation for the cast and mother education has an impact on their knowledge.

\section{Conclusion}

Current study results concluded that mothers in the study group who received nursing instructions had a higher overall mean score of clubfoot knowledge and practices and care for their infants with a casting rather than a control group. As well as the infants of the mothers who received the nursing instructions, there are fewer complications of casting and better outcomes. The study results also concluded that, there was a statistically significant positive correlation between the overall mean score of mothers' knowledge and practice in the study group and their age and level of education.

\section{Recommendations}

Based on the results of the current study, it was recommended that:

- Raising the awareness of mothers about caring infant with clubfoot through the health education program on cast care, hygienic care, nutrition, activity, treatment and child outcomes.

- Simple Arabic illustrated booklet on cast care should be available and distributed to mothers in orthopedic outpatient clinics at Cairo University Specialized Pediatric Hospital (CUSPH).

- Longitudinal study is necessary to monitor the late-cast complications and long- term outcomes.

\section{Acknowledgement}

The researchers acknowledged all mothers and their infants who participated in this study. As well as the team at Cairo University Specialized Pediatric Hospital's pediatric orthopedic clinic to facilitate working with mothers.

\section{References}

1. Nemours Foundation. Clubfoot for specific medical advice, diagnoses and treatment 2019. https://kidshealth.org/en/parents/clubfoot.html

2. Balasankara G, Ameersingb L, Al-Jumailya A. Current conservative management and classification of club foot: University, Hong Kong, China Journal of Pediatric Rehabilitation Medicine: An Interdisciplinary Approach 2016. DOI 10.3233/PRM-160394 IOS Press

3. Teklay H, Asmare Y, Kifle M, Abraha M, Baraki Z, Fissiha B et al. Treatment of congenital clubfoot and its outcome in Mekelle hospital, Tigray, Ethiopia 2018;4:1-7. www.edoriumjournals.com/ej/dr

4. University of Lowa Health Care. Parents of children born with clubfeet 2019. https://uichildrens.org/healthlibrary/parents-children-born-clubfeet

5. Chotigavanichaya C, Eamsobhana P. Complications Associated with Ponseti Serial Casting and Surgical Correction via Soft Tissue Release in Congenital Idiopathic Clubfoot. J Med Assoc Thai 2016;99(11). Journal: http://www.jmatonline.com 
6. University of Iowa Health Care. To parents of children born with clubfeet 2017. https://uichildrens.org/healthlibrary/parents-children-born-clubfeet

7. Caris E, Hampus H, Jane M, Birhanu A, Hansen L, Christopher B. Cost-effectiveness of club-foot treatment in low-income and middle-income countries by the Ponseti method 2016.

https://gh.bmj.com/content/bmjgh/1/1/e000023.full.pdf

8. Ganesan B, Luximon A, Al-Jumaily A, Balasankar SK, Naik GR. Ponseti method in the management of clubfoot under 2 years of age: A systematic review. PLoS One 2017;12(6):e0178299.

doi: 10.1371/journal.pone.0178299. PMID: 28632733; PMCID: PMC5478104

9. Reid LN. The Ponseti Method: Casting Phase. Kids Health Nemours Foundation 2017. https://kidshealth.org/en/parents/ponseti-casting.html

10. Drew S, Lavy C, Gooberman R. What Factors Affect Patient Access and Engagement with Clubfoot Treatment in Lowand Middle Income Countries? Meta Synthesis of Existing Qualitative Studies using a Social Ecological Model. Tropical Medicine \& International Health 2016;21(5):570-89.

11. Global Cluboot Initiative. Ending Clubfoot Disability: A Global Strategy 2017. http:/globalclubfoot.com/wp-content/uploads

12. Burns N, Grove S. Understanding Nursing Research Building an Evidence-Based Practice. (5th ed) USA: Elsevier 2017, P35- 61.

13. International Fund for Agricultural Institution. Calculating the Sample Size 2015. http://www. ifad.org/gender/tools/hfs/anthropometry

14. Mohan S, Kumar S, Prashanth L. Krishnagopal. Management of idiopathic clubfoot by Ponseti's technique. International Journal of Orthopaedics Sciences 2018;4(1):92-97.

DOI: https://doi.org/10.22271/ortho.2018.v4.i1b.16

15. Roy D. Pediatric Clinical Advisor Clubfoot. 2nd edition.

https://www.sci encedirect .com/topics/medicine-anddentistry/clubfoot 2016.

16. Su Y, Xie Y, Kang X, Nan G. A polyaxial fixation brace for the treatment of idiopathic congenital talipes equinovarus in newborns. J Orthop Surg Res 2019;14(1):211.

doi: 10.1186/s13018-019-1268-9. PMID: 31300013; PMCID: PMC6625020

17. Manisha R, Priyanka K. Congenital Clubfoot: A Comprehensive Review. MM Institute of Nursing, Maharishi 2017.

https://juniperpublishers .com/ oroaj/pdf /OROAJ .MS.ID.555728.pdf

18. Simerpal K, Broussard C. Devine O, Green R, Sonja A, Reefhuis J. Association between Maternal Age and Birth Defects of Unknown Etiology - United States, Published in final edited form as: Birth Defects Res A Clin Mol Teratol 2015;94(12):1010-1018. doi:10.1002/bdra.23049

19. Alam Z, Haque M, Bhuiyan R, Islam Sh. Islam M, Pradhania M. Assessing Knowledge on Clubfoot Among Parents Having Children with Clubfoot Deformity. ChattagramMaa-O-Shishu Hospital Medical College Journal 2015;14(1).
20. Shalaby K, Diab A, Ismail F. Population Situation Analysis Egypt 2016.

https://egypt.unfpa.org/ sites/ default/files/pubpdf/PSA\%20Final.pdf

21. Mohamed AN, Mohamed A. Improving Knowledge, Attitude and Home Care of Mothers Regarding Children with Congenital Anomalies, Faculty of Nursing, Beni-Suef University, IOSR Journal of Nursing and Health Science (IOSR-JNHS) e-ISSN: 2320-1959. p-ISSN: 2320-1940 2019;8(1):72-82. www.iosrjournals.org

22. Malagelada F, Mayet S, Firth G, Ramachandran M. The impact of the Ponseti treatment method on parents and caregivers of children with clubfoot: a comparison of two urban populations in Europe and Africa. J Child Orthop 2016:10(2):101-107. doi: 10.1007/s11832-0160719-7

23. Smythe TD, Bruce J, Kuper H, Lavy C, Foster A. Results of clubfoot treatment after manipulation and casting using the Ponseti method: experience in Harare, Zimbabwe. Trop Med Int Health 2016;21:1311-1388. doi:10.1111/tmi.12750

24. Cooke SJ, Balain B, Kerin CC, Kiely NT. Clubfoot 2018, P139-149.

http://www.wessexdeanery.nhs.uk/PDF/CTEV.pdf

25. Pavone V, Testa G, Costarella L, Pavone P, Sessa G. Congenital idiopathic talipesequinovarus: An evaluation in infants treated by the Ponseti method. Eur Rev Med Pharmacol Sci 2015;17(9):2675-9.

26. Chotigavanichaya C, Eamsobhana P, Ariyawatkul T, Saelim C, Kaewpornsawan K. Complications Associated with Ponseti Serial Casting and Surgical Correction via Soft Tissue Release in Congenital Idiopathic Clubfoot. J Med Assoc Thai 2016; 99(11):1192-7.

27. Wanjiru N. Experiences of Parents/Caregivers of Children with Congenital Talipes Equinovarus: A Qualitative Study. Annals of Physiotherapy Clinics 2018;1(2):1006.

28. Auliel VS, Halvorsen VB, Brox JI. Motor abilities in 182 children treated for idiopathic clubfoot: a comparison between the traditional and the Ponseti method and controls. J Child Orthop 2018;12:383-389.

29. Troeme NH, Wolfe D. Child maltreatment in Canada: selected results from the Canadian Incidence Study of Reported Child Abuse and Neglect. WORLD REPORT ON Violenceand Health Ottawa, Minister of Public Works and Government Services Canada 2015.

30. Wong D, Hockenberry M. Nursing care of infant and children. Mosby: London 2017, 1071-1072. 